Alma Mater Studiorum - Università di Bologna DEPARTMENT OF ECONOMICS

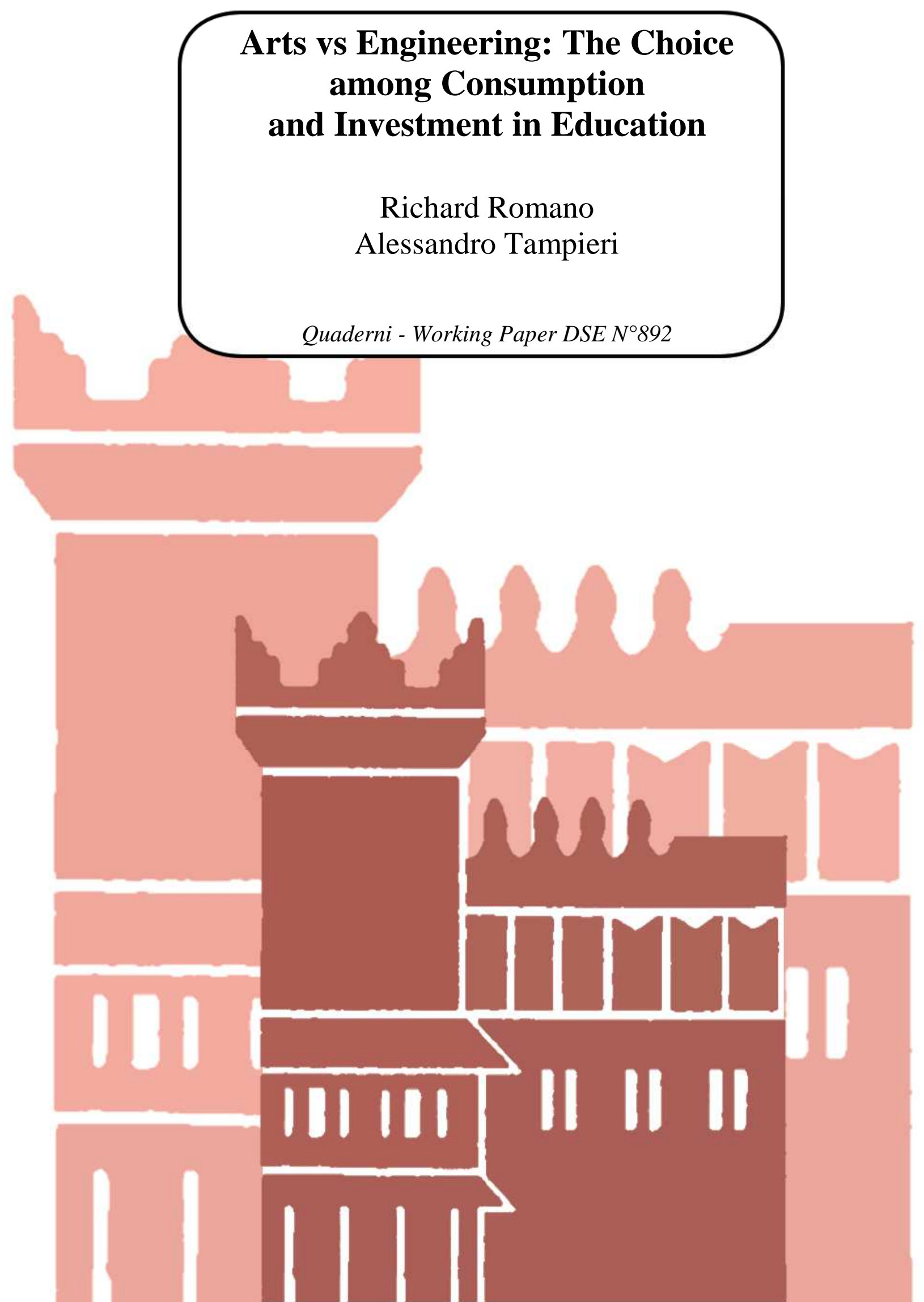




\title{
Arts vs Engineering: The Choice among Consumption and Investment in Education ${ }^{*}$
}

\author{
[ Preliminary ]
}

Richard Romano $^{\dagger}$ and Alessandro Tampieri ${ }^{\ddagger}$

\begin{abstract}
In this paper we develop a model in which students choose their university courses according to both investment and consumption incentives. We show that in the private problem, the education decisions are inefficient compared to the social optimum. The result is driven by the fact that students do not consider an externality of acquiring education for investment purposes in the working environment. We show that it is possible to design tuition fees in such a way that students acquire the socially optimal level of education.
\end{abstract}

JEL Numbers: D62; H21; I21.

Keywords: education consumption; education investment; tuition fees discrimination.

\footnotetext{
* We would like to thank the audience seminar at the University of Florida 2013 for comments and suggestions. The usual disclaimer applies.

† Warrington College of Business Administration, University of Florida, email: richard.romano@warrington.ufl.edu.

\$ Department of Economics, University of Bologna, email: tamp79@gmail.com.
} 


\section{Introduction}

In the literature of economics of education, the theory of human capital assumes that investments in education directly increase a worker's productivity (Becker, 1993). One aspect that does not emerge from the theory of human capital is that education may be acquired in part as a consumption good. This can be seen in many ways:

1. University curricula vary widely in the job prospects after graduation. Students are often observed choosing majors and courses with low job opportunities. This is not for lack of information. A student has a multitude of information about job opportunities in each field of study. For example, it is widely acknowledged that the job opportunities associated with pursuing an engineering degree are more favorable compared to those of an art degree. Interpreting education as a consumption good can help explain the attendance at university courses that have weaker job prospects. In the example considered, a student may find taking an art course more enjoyable than an engineering course. However, the student faces a trade-off based upon their future job prospects when choosing between these two courses.

2. There is a relationship between income and the education acquired by an individual. This relationship refers both to the amount of education acquired and to the choice of curricula. In both cases, interpreting education as a consumption good may explain this relationship:

a. First, the acquisition of education increases with income (Becker, 1967, 1993, McMahon, 1976, 1984, and 1991, Acemoglu and Pischke, 2001, Blanden and Machin, 2004, Vona, 2011, inter alia). The economic literature offers three explanations for this: financial constraints; pre-existing ability differences correlated with parental income (due to non-cognitive skills acquired from the environment in which a student is raised) and differences in risk aversion, without reaching a uniform consensus (Ellwood and Kane 2000, Cameron and Heckman 2001, Carneiro and Heckman 2002). The empirical evidence is consistent with the alternative interpretation that education may be considered as a (normal or luxury) consumption good rather than a pure investment good.

b. Second, there is a relationship between the choice of courses and the student's household income. Parents with lower income levels are more likely to encourage their child to choose university courses that are associated with more promising job prospects, regardless of the child's preferences. Given this parental pressure, a poor student is more likely to choose a university course that can increase her opportunities in the job market. There is some evidence supporting this statement. Baird (1967), in a study based on a comparative socioeconomic analysis of 18,378 prospective college students, found that students from higher income homes were relatively more concerned with developing their intellect, while students from less affluent households were more concerned with vocational and professional training. The Baird (1967)'s results are confirmed by Dealney (1998), in which lower income students are more concerned about how college will prepare them for a career. Trusty et al. (2000) studied the dataset NELS:88 from the 1988 to 1994 panel sample of the NELS:88. The sample used represents U.S. students who indicated a specific major field of study at postsecondary institution when they were 2 years beyond high school. They show that, at the highest level of socio-economic status, increases in academic performance resulted in a decrease in the choice of enterprising-related majors. Leppel et al. (2001) examine the data based on the 1990 survey of Beginning Postsecondary Students (BPS), that follows a group of students who began their postsecondary educational careers during academic year 1989-90. They show that an increase in socio-economic status of the families of college students would be good news for humanities and social science departments, but bad news for education and 
science and engineering. ${ }^{1}$ Leppel et al. (2005) exploit the National Longitudinal Survey of Youth in order to examine processes by which students enter lucrative fields of study, selective colleges, and lucrative fields within selective colleges. They shows that students from families with high socio-economic status have a much greater probability of selecting lower income fields. Interpreting education as a consumption good may explain this evidence: poor students are more likely to choose education with stronger investment characteristics than rich students.

To the best of our knowledge, this is the first analysis on educational choices in which education is explicitly modeled as a consumption or investment good. The analysis can provide input to the design an efficient educational policy. A question that may arise is why university courses that are associated with weaker job prospects should be subsidized. Similarly, should tuition fees be the same for university courses that differentially affect a student's career? The aim of this paper is to address such questions.

We develop a model in which a student acquires education both with consumption and investment features. Acquiring education investment has a positive effect on the general productivity in the working environment as well as on an individual's productivity (Benabou, 1996). Thus, investment in education is associated with a positive externality. However, when a student chooses its levels of consumption and investment education, this externality is not taken into account. As a consequence, in the private equilibrium a student acquires too little educational investment, compared to the social optimum.

The paper considers next possible government interventions in order to reach the social optimum, in the form of (i) regulated tuition fees or (ii) regulated levels of education. Our results show that it is possible to either manipulate tuition fees or set a minimum level of education in such a way that students acquire the social optimum level of education. In the case with regulated tuition fees, this result emerges if tuition fees for education consumption are kept at the marginal production cost of providing education, whereas the tuition fees for education investment are set below marginal production cost.

The paper can provide a theoretical understanding on the empirical literature of heterogeneous human capital and heterogeneity in the returns of education. In this strand Antonji et al. (2012) and Yamaguchi (2012) provide some recent contributions and new evidence, while and Sanders and Taber (2012) offer a review of the literature.

The paper offers a theoretical support to policies in favor of STEM (science, technology. engineering and mathematics) education. An example of such policies is the 2007 "America Competes Act" (P.L. 110-69), which responds to concerns that the United States may not be able to compete economically with other nations in the future due to insufficient investment today in STEM education and workforce development, and it is intended to increase the nation's investment in STEM education from kindergarten to graduate school and postdoctoral education. The act authorizes funding increases for the National Science Foundation (NSF), National Institute of Standards and Technology (NIST) laboratories, and the Department of Energy (DOE) Office of Science.

The remainder of the paper is organized as follows. Section 2 presents the model. Section 3 shows the difference between a private and a socially optimal equilibrium. Section 4 considers possible

${ }^{1}$ Both the NELS:88 and the BPS were conducted by the National Center for Education Statistics (NCES) of the U.S. Department of Education. 
government interventions, in particular either (i) the design of optimal tuition fees or (ii) the introduction of a minimum (optimal) level of education investment. Section 5 concludes.

\section{The model}

Students differ in ability $\theta$ and household income $Y_{0}$. We denote the distribution of $\theta$ as $G(\theta)$, assumed to be continuous and positive on the support $\theta \in[0, \bar{\theta}]$, with density function $g(\theta)$, whereas the joint distribution on student type $\left(\theta, Y_{0}\right)$ is continuous and given by $F\left(\theta, Y_{0}\right)$, with joint density function $f\left(\theta, Y_{0}\right)$, assumed to be positive on its support $[0, \bar{\theta}] \times\left[0, \bar{Y}_{0}\right]$.

There are two periods. In period 0 , students attend college. In period 1 , they work and obtain an income. When students attend college, they decide the amount and type of education they want to acquire. The specific feature of this model is that education can be acquired for two different reasons: (i) for investment reasons, i.e., education can be acquired for increasing future income, and (ii) for consumption reasons. An individual may be interested in a specific topic, they may want to acquire glamour by increasing their conversational arguments, they may want to acquire social status given by obtaining a college degree, even though this will not improve their future incomes. In this view, a student can choose a course because it is interesting, or easier to prepare, even though it does not give many job opportunities.

In college, different courses of study present different proportions of these two elements of education. This is due for instance to different labour demand for a certain topic (engineers may be more required than art experts, or they may be paid better), or to a general interest from a social point of view toward other topics (talking about arts, cinema, philosophy, literature may be considered in general more interesting that discussing about mathematics). Notice that labelling courses is irrelevant for our analysis. In the future, people may find more socially intriguing a mathematician than an artist, and labour market may need more philosophers than engineers, and still our analysis will hold.

For generality, instead of referring to specific courses, we denote the amount of education acquired for consumption as $e_{1}$, with unitary tuition fees $t_{1}>0$, and the amount of education acquired for investment as $e_{2}$, with unitary tuition fees $t_{2}>0$. We do not put constraints on the amount of education to acquire in order to obtain a degree. Even though a degree requires usually a specific amount of courses, a student may attend only one year, or keep studying at a master program, or attend a short term course, or a summer school.

There is a number of colleges that perfectly compete in the college market. Therefore colleges set their unitary tuition fees in such a way as to cover their marginal resource cost, $t_{i}=c_{i}$, where $c_{i}$ is the marginal resource cost of providing teaching for every course type $i \in\{1,2\}$. We assume for generality that the marginal resource cost of providing a course of type 1 is the same as providing a course of type 2 , so that $t_{1}=t_{2}$.

Students have a utility function over numeraire consumption $c_{0}$, savings $s$, education consumption $e_{1}$ and education investment $e_{2}$ :

$U=\alpha \ln \left(\theta^{\beta} e_{1}^{1-\beta}\right)+\gamma \ln \left(c_{0}\right)+k \ln (y)$ 
where $\ln \left(\theta^{\beta} e_{1}^{1-\beta}\right)$ denotes the benefit obtained by consuming education, being increasing with a student's ability, $y$ denotes the future earnings and $\alpha, \gamma, k>0$ are the respective weights. In particular earnings are given by:

$$
y=\left(\theta e_{2}\right)^{\frac{\sigma-1}{\sigma}} E^{\frac{1}{\sigma}}+s(1+r)
$$

where $\left(\theta e_{2}\right)^{\frac{\sigma-1}{\sigma}} E^{\frac{1}{\sigma}}$ is income, $\sigma>1$, savings $s \in \mathfrak{R}$ (borrowings if negative) are accumulated in period $0, r$ is interests rate, and

$$
E=\left(\iint\left(\theta e_{2}\right)^{\frac{\sigma-1}{\sigma}} f\left(\theta, Y_{0}\right) d \theta d Y_{0}\right)^{\frac{\sigma}{\sigma-1}}
$$

Income is increasing in ability and education investment. Following Benabou (1996), we assume that each worker's income depend positively on a simple index of human capital of the population. Accordingly, highly educated and skilled colleagues will boost the productivity of an individual and in turn his/her own income. This interdependence is caught by $\sigma$, which measures the elasticity of substitution. $^{2}$

In equilibrium, students maximize their own utility by choosing their amount of consumption $c_{0}$, savings $s$, education consumption $e_{1}$ and education investment $e_{2}$, subject to the budget constraint

$Y_{0}=c_{0}+t_{1} e_{1}+t_{2} e_{2}+\psi_{1}\left(e_{1}\right)+\psi_{2}\left(e_{2}\right)+s$

where $\psi_{i}\left(e_{i}\right)$ is the time cost of education for every course type $i \in\{1,2\}$, and $\psi^{\prime}{ }_{i}(),. \psi^{\prime \prime}{ }_{i}()>$.0 .

\section{Private vs social optimum}

In this section we investigate the baseline results of the paper. In particular we will compare the private equilibrium, i.e., the equilibrium occurring with no government intervention, with the socially optimal allocation. For every student type $\left(\theta, Y_{0}\right)$, the private problem is:

\footnotetext{
${ }^{2}$ This can be easily seen by remembering that the elasticity of substitution between an individual of type $\theta$ and an individual of type $\theta^{\prime}$ acquiring educational investment $e_{2}$ and $e_{2}^{\prime}$, respectively, is given by

$$
\varepsilon=\frac{d \ln \left(\frac{e_{2}^{\prime}}{e_{2}}\right)}{d \ln (M T R S)}=\frac{\frac{e_{2}}{e_{2}^{\prime}}}{\frac{1}{\sigma}\left(\frac{e_{2}}{e_{2}^{\prime}}\right)}
$$

Simple algebra shows that $\mathcal{E}=\sigma$.
} 


$$
\begin{aligned}
& \int \max _{c_{0}, e_{1}, e_{2}, s} \alpha \ln \left(\theta^{\beta} e_{1}^{1-\beta}\right)+\gamma \ln \left(c_{0}\right)+k \ln (y) \\
& \text { s.t. } \quad y=\left(\theta e_{2}\right)^{\frac{\sigma-1}{\sigma}} E^{\frac{1}{\sigma}}+s(1+r) \\
& E=\left(\iint\left(\theta e_{2}\right)^{\frac{\sigma-1}{\sigma}} f\left(\theta, Y_{0}\right) d \theta d Y_{0}\right)^{\frac{\sigma}{\sigma-1}} \\
& Y_{0}=c_{0}+t_{1} e_{1}+t_{2} e_{2}+\psi_{1}\left(e_{1}\right)+\psi_{2}\left(e_{2}\right)+s
\end{aligned}
$$

To solve the problem, write the Lagrangian function:

$$
\begin{aligned}
& L^{P}=\alpha \ln \left(\theta^{\beta} e_{1}^{1-\beta}\right)+\gamma \ln \left(c_{0}\right)+k \ln \left(\left(\theta e_{2}\right)^{\frac{\sigma-1}{\sigma}} E^{\frac{1}{\sigma}}+s(1+r)\right)+ \\
& \lambda_{1}\left[Y_{0}-\left(c_{0}+t_{1} e_{1}+t_{2} e_{2}+\psi_{1}\left(e_{1}\right)+\psi_{2}\left(e_{2}\right)+s\right)\right]
\end{aligned}
$$

The first order conditions with respect to $c_{0}, e_{1}, e_{2}, s$ and $\lambda_{1}$ are:

$$
\begin{aligned}
& \frac{\partial L^{P}}{\partial c_{0}}=\frac{\gamma}{c_{0}}-\lambda_{1}=0, \\
& \frac{\partial L^{P}}{\partial e_{1}}=\frac{\alpha(1-\beta)}{e_{1}}-\lambda_{1}\left(t_{1}+\psi_{1}^{\prime}\left(e_{1}\right)\right)=0, \\
& \frac{\partial L^{P}}{\partial e_{2}}=\frac{\sigma-1}{\sigma} \frac{k e_{2}^{-\frac{1}{\sigma}} \theta^{\frac{\sigma-1}{\sigma}} E^{\frac{1}{\sigma}}}{\left(\theta e_{2}\right)^{\frac{\sigma-1}{\sigma}} E^{\frac{1}{\sigma}}+s(1+r)}-\lambda_{1}\left(t_{2}+\psi_{2}^{\prime}\left(e_{2}\right)\right)=0, \\
& \frac{\partial L^{P}}{\partial s}=\frac{k(1+r)}{\left(\theta e_{2}\right)^{\frac{\sigma-1}{\sigma}} E^{\frac{1}{\sigma}}+s(1+r)}-\lambda_{1}=0, \\
& \frac{\partial L^{P}}{\partial \lambda_{1}}=Y_{0}-\left(c_{0}+t_{1} e_{1}+t_{2} e_{2}+\psi_{1}\left(e_{1}\right)+\psi_{2}\left(e_{2}\right)+s\right) .
\end{aligned}
$$

Consider (9), which amounts to:

$$
\lambda_{1}=\frac{k(1+r)}{\left(\theta e_{2}\right)^{\frac{\sigma-1}{\sigma}} E^{\frac{1}{\sigma}}+s(1+r)} .
$$

Substituting (11) into (8) and obtain

$$
\frac{\sigma-1}{\sigma} \frac{k e_{2}^{-\frac{1}{\sigma}} \theta^{\frac{\sigma-1}{\sigma}} E^{\frac{1}{\sigma}}}{\left(\theta e_{2}\right)^{\frac{\sigma-1}{\sigma}} E^{\frac{1}{\sigma}}+s(1+r)}-\frac{k(1+r)\left(t_{2}+\psi_{2}^{\prime}\left(e_{2}\right)\right)}{\left(\theta e_{2}\right)^{\frac{\sigma-1}{\sigma}} E^{\frac{1}{\sigma}}+s(1+r)}=0
$$




$$
\frac{\sigma-1}{\sigma} \frac{e_{2}^{-\frac{1}{\sigma}} \theta^{\frac{\sigma-1}{\sigma}} E^{\frac{1}{\sigma}}}{(1+r)}=t_{2}+\psi_{2}^{\prime}\left(e_{2}\right)
$$

Condition (13) shows that the discounted marginal benefit equals marginal cost today. Consider next (6), which amounts to

$$
\lambda_{1}=\frac{\gamma}{c_{0}}
$$

Plugging (14) into (7) yields:

$$
\frac{c_{0}}{\gamma} \frac{\alpha(1-\beta)}{e_{1}}=t_{1}+\psi_{1}^{\prime}\left(e_{1}\right)
$$

according to which the marginal benefit of consuming education equals marginal cost. Therefore the levels of education acquired in the private case are

Proposition 1. For every $\left(\theta, Y_{0}\right)$ student, the individually optimal levels of education in equilibrium are $e_{1}^{P}$ such that:

$$
\frac{c_{0}}{\gamma} \frac{\alpha(1-\beta)}{e_{1}}=t_{1}+\psi_{1}^{\prime}\left(e_{1}\right)
$$

and $e_{2}^{P}$ such that:

$$
\frac{\sigma-1}{\sigma} \frac{e_{2}^{-\frac{1}{\sigma}} \theta^{\frac{\sigma-1}{\sigma}} E^{\frac{1}{\sigma}}}{(1+r)}=t_{2}+\psi_{2}^{\prime}\left(e_{2}\right)
$$

Notice that $c_{0}$ is function of household income $Y_{0}$, in particular $\frac{c_{0}}{\gamma}$ can be rewritten as:

$$
\frac{Y_{0}-\left(t_{1} e_{1}+t_{2} e_{2}+\psi_{1}\left(e_{1}\right)+\psi_{2}\left(e_{2}\right)+s\right)}{\gamma} .
$$

Differentiating the L.H.S. of equation (16) with respect to $Y_{0}$ yields

$$
\frac{\partial L^{P}}{\partial e_{1} \partial Y_{0}}=\frac{1}{\gamma}>0
$$

This shows that the choice of education consumption depends on households income, and in particular $e_{1}^{P}$ is higher the higher the $Y_{0}$. Conversely, equation (17) depends on a student's ability but not on her household's income. Finally, by equating:

$$
\lambda_{1}=\frac{k(1+r)}{\left(\theta e_{2}\right)^{\frac{\sigma-1}{\sigma}} E^{\frac{1}{\sigma}}+s(1+r)}=\frac{\gamma}{Y_{0}-\left(t_{1} e_{1}+t_{2} e_{2}+\psi_{1}\left(e_{1}\right)+\psi_{2}\left(e_{2}\right)+s\right)},
$$


and solving for s yields:

$$
s=\frac{k(1+r)\left[Y_{0}-\left(t_{1} e_{1}+t_{2} e_{2}+\psi_{1}\left(e_{1}\right)+\psi_{2}\left(e_{2}\right)\right)\right]-\gamma\left(\theta e_{2}\right)^{\frac{\sigma-1}{\sigma}} E^{\frac{1}{\sigma}}}{(1+k)(1+r)},
$$

which is the amount of savings in equilibrium.

We turn now to consider the social problem and characterize Pareto efficient allocations. Let $\omega\left(\theta, Y_{0}\right)>0$ denote the weight on student $\left(\theta, Y_{0}\right)$ 's utility in the social welfare function, and let $T_{0}\left(\theta, Y_{0}\right)\left(T\left(\theta, Y_{0}\right)\right)$ denote the planner's monetary transfer to household $\left(\theta, Y_{0}\right)$ and $\iint T_{0}\left(\theta, Y_{0}\right) f\left(\theta, Y_{0}\right) d \theta d Y_{0}\left(\iint T\left(\theta, Y_{0}\right) f\left(\theta, Y_{0}\right) d \theta d Y_{0}\right)$ the total transfer to students in time 0 (1). The following condition, representing the government balanced budget, must hold:

$$
\begin{aligned}
& \iint t_{1} e_{1} f\left(\theta, Y_{0}\right) d \theta d Y_{0}+\iint t_{2} e_{2} f\left(\theta, Y_{0}\right) d \theta d Y_{0}+\iint T_{0}\left(\theta, Y_{0}\right) f\left(\theta, Y_{0}\right) d \theta d Y_{0}+ \\
& \frac{1}{1+r} \iint T\left(\theta, Y_{0}\right) f\left(\theta, Y_{0}\right) d \theta d Y_{0}=0
\end{aligned}
$$

The social planner chooses consumption $c_{0}\left(\theta, Y_{0}\right)$, savings $s\left(\theta, Y_{0}\right)$, amount of education consumption and investment $e_{1}\left(\theta, Y_{0}\right)$ and $e_{2}\left(\theta, Y_{0}\right)$, and balanced-budget transfers $T_{0}\left(\theta, Y_{0}\right)$ and $T\left(\theta, Y_{0}\right)$ so as to maximize the social welfare function:

$$
W\left(c_{0}, s, e_{1}, e_{2}, T_{0}, T\right)=\iint \omega\left(\theta, Y_{0}\right)\left[\alpha \ln \left(\theta^{\beta} e_{1}^{1-\beta}\right)+\gamma \ln \left(c_{0}\right)+k \ln \left(y+T\left(\theta, Y_{0}\right)\right)\right] f\left(\theta, Y_{0}\right) d \theta d Y_{0}
$$

A solution of the problem is Pareto efficient for any social welfare weights $\omega\left(\theta, Y_{0}\right)$. If a Pareto improvement were feasible relative to any solution, then the objective function would increase with the change, so that a contradiction would emerge. As the social weights vary, alternative Pareto efficient allocations are determined, since as one moves along the Paretian frontier the slope changes, which serve as social welfare weights corresponding to the particular Pareto efficient allocation. If the utility possibilities set is convex, then all Pareto efficient allocations are a solution to the problem for some set of weights. ${ }^{3}$ Therefore the social planner's problem is

$$
\begin{cases}\max _{c_{0}, e_{1}, e_{2}, s} & W\left(c_{0}, s, e_{1}, e_{2}, T_{0}, T\right) \\ \text { s.t. } & y=\left(\theta e_{2}\right)^{\frac{\sigma-1}{\sigma}} E^{\frac{1}{\sigma}}+s(1+r) \\ & E=\left(\iint\left(\theta e_{2}\right)^{\frac{\sigma-1}{\sigma}} f\left(\theta, Y_{0}\right) d \theta d Y_{0}\right)^{\frac{\sigma}{\sigma-1}} \\ & Y_{0}=c_{0}+\psi_{1}\left(e_{1}\right)+\psi_{2}\left(e_{2}\right)+s+T_{0}\left(\theta, Y_{0}\right) \\ & \iint t_{1} e_{1} f\left(\theta, Y_{0}\right) d \theta d Y_{0}+\iint t_{2} e_{2} f\left(\theta, Y_{0}\right) d \theta d Y_{0}+ \\ & \iint T_{0}\left(\theta, Y_{0}\right) f\left(\theta, Y_{0}\right) d \theta d Y_{0}+\frac{1}{1+r} \iint T\left(\theta, Y_{0}\right) f\left(\theta, Y_{0}\right) d \theta d Y_{0}=0\end{cases}
$$

\footnotetext{
${ }^{3}$ If the utilities possbilities set is not convex, then one can still find all Pareto efficient allocations as extrema of the planner problem (Panzar and Willig, 1976).
} 
The Lagrangian function is:

$$
\begin{aligned}
& L^{W}=\iint \omega\left(\theta, Y_{0}\right)\left[\alpha \ln \left(\theta^{\beta} e_{1}^{1-\beta}\right)+\gamma \ln \left(c_{0}\right)\right] f\left(\theta, Y_{0}\right) d \theta d Y_{0}+ \\
& \iint \omega\left(\theta, Y_{0}\right)\left[k \ln \left(\left(\theta e_{2}\right)^{\frac{\sigma-1}{\sigma}} E^{\frac{1}{\sigma}}+s(1+r)+T\left(\theta, Y_{0}\right)\right)\right] f\left(\theta, Y_{0}\right) d \theta d Y_{0}+ \\
& \lambda_{1}\left[Y_{0}-\left(c_{0}+\psi_{1}\left(e_{1}\right)+\psi_{2}\left(e_{2}\right)+s+T_{0}\left(\theta, Y_{0}\right)\right)\right]+ \\
& \lambda_{2}\left[\iint t_{1} e_{1} f\left(\theta, Y_{0}\right) d \theta d Y_{0}+\iint t_{2} e_{2} f\left(\theta, Y_{0}\right) d \theta d Y_{0}+\right. \\
& \left.\iint T_{0}\left(\theta, Y_{0}\right) f\left(\theta, Y_{0}\right) d \theta d Y_{0}+\frac{1}{1+r} \iint T\left(\theta, Y_{0}\right) f\left(\theta, Y_{0}\right) d \theta d Y_{0}\right]+ \\
& \lambda_{3}\left[E-\left(\iint\left(\theta e_{2}\right)^{\frac{\sigma-1}{\sigma}} f\left(\theta, Y_{0}\right) d \theta d Y_{0}\right)^{\frac{\sigma}{\sigma-1}}\right]
\end{aligned}
$$

For every $\left(\theta, Y_{0}\right)$ type, the first order conditions with respect to $c_{0}, e_{1}, e_{2}, s, E, T, T_{0}, \lambda_{1}, \lambda_{2}$ and $\lambda_{3}$ are:

$$
\begin{aligned}
& \frac{\partial L^{W}}{\partial c_{0}}=\frac{\omega\left(\theta, Y_{0}\right) \gamma}{c_{0}}-\lambda_{1}=0, \\
& \frac{\partial L^{W}}{\partial e_{1}}=\frac{\omega\left(\theta, Y_{0}\right) \alpha(1-\beta)}{e_{1}}-\lambda_{1} \psi_{1}^{\prime}\left(e_{1}\right)+\lambda_{2} t_{1}=0, \\
& \frac{\partial L^{W}}{\partial e_{2}}=\omega\left(\theta, Y_{0}\right) \frac{\sigma-1}{\sigma} \frac{\left(\theta e_{2}\right)^{\frac{\sigma-1}{\sigma}} E^{\frac{1}{\sigma}}+s(1+r)+T\left(\theta, Y_{0}\right)}{k e^{-\frac{1}{\sigma}} \theta^{\frac{\sigma-1}{\sigma}} E^{\frac{1}{\sigma}}}-\lambda_{1} \psi_{2}^{\prime}\left(e_{2}\right)+\lambda_{2} t_{2}-\lambda_{3} E^{\frac{1}{\sigma}} e_{2}^{-\frac{1}{\sigma}} \theta^{\frac{\sigma-1}{\sigma}}=0, \\
& \frac{\partial L^{W}}{\partial s}=\frac{\left(\theta, Y_{0}\right) k(1+r)}{\left(\theta e_{2}\right)^{\frac{\sigma-1}{\sigma}} E^{\frac{1}{\sigma}}+s(1+r)+T\left(\theta, Y_{0}\right)}-\lambda_{1}=0, \\
& \frac{\partial L^{W}}{\partial E}=\iint \omega\left(\theta, Y_{0}\right)\left[\frac{k\left(e_{2} \theta\right)^{\frac{\sigma-1}{\sigma}} E^{\frac{1-\sigma}{\sigma}}}{\left.\sigma\left(\theta e_{2}\right)^{\frac{\sigma-1}{\sigma}} E^{\frac{1}{\sigma}}+s(1+r)+T\left(\theta, Y_{0}\right)\right)}\right] f\left(\theta, Y_{0}\right) d \theta d Y_{0}+\lambda_{3}=0,
\end{aligned}
$$$$
\frac{\partial L^{W}}{\partial T}=\frac{\omega\left(\theta, Y_{0}\right) k}{\left(\theta e_{2}\right)^{\frac{\sigma-1}{\sigma}} E^{\frac{1}{\sigma}}+s(1+r)+T\left(\theta, Y_{0}\right)}+\frac{\lambda_{2}}{(1+r)} \frac{\partial}{\partial T} \iint T\left(\theta, Y_{0}\right) f\left(\theta, Y_{0}\right) d \theta d Y_{0}=0
$$

$$
\frac{\partial L^{W}}{\partial T_{0}}=\lambda_{1}+\lambda_{2} \frac{\partial}{\partial T_{0}} \iint T_{0}\left(\theta, Y_{0}\right) f\left(\theta, Y_{0}\right) d \theta d Y_{0}=0
$$


$\frac{\partial L^{W}}{\partial \lambda_{1}}=Y_{0}-\left(c_{0}+\psi_{1}\left(e_{1}\right)+\psi_{2}\left(e_{2}\right)+s+T_{0}\left(\theta, Y_{0}\right)\right)$

$\frac{\partial L^{W}}{\partial \lambda_{2}}=\iint t_{1} e_{1} f\left(\theta, Y_{0}\right) d \theta d Y_{0}+\iint t_{2} e_{2} f\left(\theta, Y_{0}\right) d \theta d Y_{0}+$

$\iint T_{0}\left(\theta, Y_{0}\right) f\left(\theta, Y_{0}\right) d \theta d Y_{0}+\frac{1}{1+r} \iint T\left(\theta, Y_{0}\right) f\left(\theta, Y_{0}\right) d \theta d Y_{0}=0$

$\frac{\partial L^{W}}{\partial \lambda_{3}}=E-\left(\iint\left(\theta e_{2}\right)^{\frac{\sigma-1}{\sigma}} f\left(\theta, Y_{0}\right) d \theta d Y_{0}\right)^{\frac{\sigma}{\sigma-1}}=0$.

Begin by noting that (25) amounts to:

$\lambda_{1}=\frac{\omega\left(\theta, Y_{0}\right) \gamma}{c_{0}}$

Whereas(31) amounts to:

$\frac{\partial L^{W}}{\partial T_{0}}=\lambda_{1}=-\lambda_{2}$

and finally (30) amounts to:

$$
-\frac{\lambda_{2}}{(1+r)}=\frac{\omega\left(\theta, Y_{0}\right) k}{\left(\theta e_{2}\right)^{\frac{\sigma-1}{\sigma}} E^{\frac{1}{\sigma}}+s(1+r)+T\left(\theta, Y_{0}\right)}
$$

We substitute (37) into (29), yielding:

$\iint-\frac{\lambda_{2}}{(1+r)} \frac{\left(e_{2} \theta\right)^{\frac{\sigma-1}{\sigma}} E^{\frac{1-\sigma}{\sigma}}}{\sigma} f\left(\theta, Y_{0}\right) d \theta d Y_{0}+\lambda_{3}=0$

which, given $E=\left(\iint\left(\theta e_{2}\right)^{\frac{\sigma-1}{\sigma}} f\left(\theta, Y_{0}\right) d \theta d Y_{0}\right)^{\frac{\sigma}{\sigma-1}}, \quad$ it $\quad$ can $\quad$ be $\quad$ rearranged as:

$-\frac{\lambda_{2}}{(1+r)} \frac{E^{\frac{\sigma-1}{\sigma}} E^{\frac{1-\sigma}{\sigma}}}{\sigma}+\lambda_{3}=0$

$\Rightarrow \frac{\lambda_{3}}{\lambda_{2}}=\frac{1}{\sigma(1+r)}$.

Consider now (27). Plugging (37) into (27) gives:

$-\frac{\lambda_{2}}{(1+r)} \frac{\sigma-1}{\sigma} e_{2}^{-\frac{1}{\sigma}} \theta^{\frac{\sigma-1}{\sigma}} E^{\frac{1}{\sigma}}-\lambda_{1} \psi_{2}^{\prime}\left(e_{2}\right)+\lambda_{2} t_{2}-\lambda_{3} e_{2}^{-\frac{1}{\sigma}} \theta^{\frac{\sigma-1}{\sigma}} E^{\frac{1}{\sigma}}=0$ 
By substituting (36) and (40), and dividing all for $\lambda_{2}$ yields:

$$
\begin{aligned}
& \frac{\sigma-1}{\sigma} \frac{e_{2}^{-\frac{1}{\sigma}} \theta^{\frac{\sigma-1}{\sigma}} E^{\frac{1}{\sigma}}}{(1+r)}-\psi_{2}^{\prime}\left(e_{2}\right)-t_{2}+\frac{e_{2}^{-\frac{1}{\sigma}} \theta^{\frac{\sigma-1}{\sigma}} E^{\frac{1}{\sigma}}}{\sigma(1+r)}=0 . \\
& \Rightarrow \frac{e_{2}^{-\frac{1}{\sigma}} \theta^{\frac{\sigma-1}{\sigma}} E^{\frac{1}{\sigma}}}{(1+r)}=t_{2}+\psi_{2}^{\prime}\left(e_{2}\right) .
\end{aligned}
$$

Consider now (26). Substituting (36) into (26) yields:

$$
\frac{\omega\left(\theta, Y_{0}\right) \alpha(1-\beta)}{\lambda_{1} e_{1}}=\psi_{1}^{\prime}\left(e_{1}\right)+t_{1} \text {. }
$$

Plugging (25) into (44) amounts to:

$$
\frac{c_{0}}{\gamma} \frac{\alpha(1-\beta)}{e_{1}}=t_{1}+\psi_{1}^{\prime}\left(e_{1}\right) \text {. }
$$

Therefore the levels of education acquired in the social optimum case are

Proposition 2. For every $\left(\theta, Y_{0}\right)$ student, the socially optimal levels of education in equilibrium are $e_{1}^{W}$ such that:

$$
\frac{c_{0}}{\gamma} \frac{\alpha(1-\beta)}{e_{1}}=t_{1}+\psi_{1}^{\prime}\left(e_{1}\right),
$$

and $e_{2}^{W}$ such that:

$$
\frac{e_{2}^{-\frac{1}{\sigma}} \theta^{\frac{\sigma-1}{\sigma}} E^{\frac{1}{\sigma}}}{(1+r)}=t_{2}+\psi_{2}^{\prime}\left(e_{2}\right)
$$

It can be easily ascertained that the social optimum is identical to private optimum for educational consumption, given the condition for $e_{1}^{P}$ and $e_{1}^{W}$ in Propositions 1 and 2. Conversely, the difference in benefit between the private and social optimum case is given by

$$
\frac{\partial L^{W}}{\partial e_{2}}-\frac{\partial L^{P}}{\partial e_{2}}=\frac{e_{2}^{-\frac{1}{\sigma}} \theta^{\frac{\sigma-1}{\sigma}} E^{\frac{1}{\sigma}}}{\sigma(1+r)},
$$

which represents the benefit that a student obtains through the externality. The foregoing results can be summarized as follows.

Proposition 3. For educational consumption, the private and social optimum coincide. For educational investment, the private optimum has lower $e_{2}$ than in the social optimum.

The result is explained by the presence of the externality in the productivity, given by education investment. Unlike the social planner, the private individual does not take that into account in her education decision. Also, even though the education acquired for consumption is the same in the 
private and socially optimal case in absolute terms, this is in fact too high in the private case relatively to the level of education acquired for investment.

Finally notice that the weights of student types $\omega\left(\theta, Y_{0}\right)$ do not play any role in the social optimal level of $e_{2}$. This is due to the fact that $e_{2}$ is a pure investment good, so that no redistribution is necessary in order to make students reach their optimal level of $e_{2}$.

\section{Government intervention}

\subsection{The design of optimal tuition fees}

In this section we allow tuition fees to be different according to whether education is acquired for consumption or investment. In order to obtain different tuition fees, the government introduces a subsidy to education investment:

$$
\begin{aligned}
& T_{0}^{*}\left(\theta, Y_{0}\right) \equiv T_{0}-\left(m_{2}^{*} e_{2}-m_{2}^{W} e_{2}^{W}\right)+t_{1} e_{1}^{W}+t_{2} e_{2}^{W}, \\
& T^{*}\left(\theta, Y_{0}\right) \equiv T\left(\theta, Y_{0}\right),
\end{aligned}
$$

where $m_{2}^{*}$ is the per unit subsidy to education investment. The private problem becomes:

$$
\begin{cases}\max _{c_{0}, e_{1}, e_{2}, s} & \alpha \ln \left(\theta^{\beta} e_{1}^{1-\beta}\right)+\gamma \ln \left(c_{0}\right)+k \ln \left(y+T^{*}\left(\theta, Y_{0}\right)\right) \\ \text { s.t. } & y=\left(\theta e_{2}\right)^{\frac{\sigma-1}{\sigma}} E^{\frac{1}{\sigma}}+s(1+r) \\ & E=\left(\iint\left(\theta e_{2}\right)^{\frac{\sigma-1}{\sigma}} f\left(\theta, Y_{0}\right) d \theta d Y_{0}\right)^{\frac{\sigma}{\sigma-1}} \\ & Y_{0}=c_{0}+\psi_{1}\left(e_{1}\right)+\psi_{2}\left(e_{2}\right)+s+T_{0}\left(\theta, Y_{0}\right)-\left(m_{2}^{*} e_{2}-m_{2}^{W} e_{2}^{W}\right)+t_{1} e_{1}^{W}+t_{2} e_{2}^{W} \\ & \iint t_{1} e_{1} f\left(\theta, Y_{0}\right) d \theta d Y_{0}+\iint t_{2} e_{2} f\left(\theta, Y_{0}\right) d \theta d Y_{0}+ \\ & \iint T_{0}\left(\theta, Y_{0}\right) f\left(\theta, Y_{0}\right) d \theta d Y_{0}+\frac{1}{1+r} \iint T\left(\theta, Y_{0}\right) f\left(\theta, Y_{0}\right) d \theta d Y_{0}=0\end{cases}
$$

To solve the problem, write the Lagrangian function (the superscript $R$ stands for "regulated"):

$$
\begin{aligned}
& L^{R}=\alpha \ln \left(\theta^{\beta} e_{1}^{1-\beta}\right)+\gamma \ln \left(c_{0}\right)+k \ln \left(\left(\theta e_{2}\right)^{\frac{\sigma-1}{\sigma}} E^{\frac{1}{\sigma}}+s(1+r)+T\left(\theta, Y_{0}\right)\right)+ \\
& \lambda_{1}\left[Y_{0}-\left(c_{0}+\psi_{1}\left(e_{1}\right)+\psi_{2}\left(e_{2}\right)+s+T_{0}\left(\theta, Y_{0}\right)-\left(m_{2}^{*} e_{2}-m_{2}^{W} e_{2}^{W}\right)+t_{1} e_{1}^{W}+t_{2} e_{2}^{W}\right)\right]+ \\
& \lambda_{2}\left[\iint t_{1} e_{1} f\left(\theta, Y_{0}\right) d \theta d Y_{0}+\iint t_{2} e_{2} f\left(\theta, Y_{0}\right) d \theta d Y_{0}+\right. \\
& \left.\iint T_{0}\left(\theta, Y_{0}\right) f\left(\theta, Y_{0}\right) d \theta d Y_{0}+\frac{1}{1+r} \iint T\left(\theta, Y_{0}\right) f\left(\theta, Y_{0}\right) d \theta d Y_{0}\right]
\end{aligned}
$$

the first order conditions with respect to $c_{0}, e_{1}, e_{2}, s, T, T_{0}, \lambda_{1}$ and $\lambda_{2}$ are:

$$
\frac{\partial L^{R}}{\partial c_{0}}=\frac{\gamma}{c_{0}}-\lambda_{1}=0,
$$




$$
\begin{aligned}
& \frac{\partial L^{R}}{\partial e_{1}}=\frac{\alpha(1-\beta)}{e_{1}}-\lambda_{1} \psi_{1}^{\prime}\left(e_{1}\right)+\lambda_{2} t_{1}=0 \\
& \frac{\partial L^{R}}{\partial e_{2}}=\frac{\sigma-1}{\sigma} \frac{k e_{2}^{-\frac{1}{\sigma}} \theta^{\frac{\sigma-1}{\sigma}} E^{\frac{1}{\sigma}}}{\left(\theta e_{2}\right)^{\frac{\sigma-1}{\sigma}} E^{\frac{1}{\sigma}}+s(1+r)+T\left(\theta, Y_{0}\right)}-\lambda_{1}\left(\psi_{2}^{\prime}\left(e_{2}\right)-m_{2}^{*}\right)+\lambda_{2} t_{2}=0 \\
& \frac{\partial L^{R}}{\partial s}=\frac{k(1+r)}{\left(\theta e_{2}\right)^{\frac{\sigma-1}{\sigma}} E^{\frac{1}{\sigma}}+s(1+r)+T\left(\theta, Y_{0}\right)}-\lambda_{1}=0 \\
& \frac{\partial L^{R}}{\partial T}=\frac{k}{\left(\theta e_{2}\right)^{\frac{\sigma-1}{\sigma}} E^{\frac{1}{\sigma}}+s(1+r)+T\left(\theta, Y_{0}\right)}+\frac{\lambda_{2}}{(1+r)}=0 \\
& \frac{\partial L^{R}}{\partial T_{0}}=\lambda_{1}+\lambda_{2} \frac{\partial \iint T_{0}\left(\theta, Y_{0}\right) f\left(\theta, Y_{0}\right) d \theta d Y_{0}}{\partial T_{0}}=0, \\
& \frac{\partial L^{R}}{\partial \lambda_{1}}=Y_{0}-\left(c_{0}+\psi_{1}\left(e_{1}\right)+\psi_{2}\left(e_{2}\right)+s+T_{0}\left(\theta, Y_{0}\right)-\left(m_{2}^{*} e_{2}-m_{2}^{W} e_{2}^{W}\right)+t_{1} e_{1}^{W}+t_{2} e_{2}^{W}\right), \\
& \frac{\partial L^{R}}{\partial \lambda_{2}}=\iint t_{1} e_{1} f\left(\theta, Y_{0}\right) d \theta d Y_{0}+\iint t_{2} e_{2} f\left(\theta, Y_{0}\right) d \theta d Y_{0}+ \\
& \iint T_{0}\left(\theta, Y_{0}\right) f\left(\theta, Y_{0}\right) d \theta d Y_{0}+\frac{1}{1+r} \iint T\left(\theta, Y_{0}\right) f\left(\theta, Y_{0}\right) d \theta d Y_{0}=0
\end{aligned}
$$

Begin by noting that (52) amounts to:

$$
\lambda_{1}=\frac{\gamma}{c_{0}}
$$

(57) amounts to $\lambda_{1}=-\lambda_{2}$, and (56) amounts to:

$$
-\frac{\lambda_{2}}{(1+r)}=\frac{k}{\left(\theta e_{2}\right)^{\frac{\sigma-1}{\sigma}} E^{\frac{1}{\sigma}}+s(1+r)+T\left(\theta, Y_{0}\right)}
$$

Consider now (54). Plugging $\lambda_{1}=-\lambda_{2}$ and (61), equation (54) is:

$$
\frac{(\sigma-1) e_{2}^{-\frac{1}{\sigma}} \theta^{\frac{\sigma-1}{\sigma}} E^{\frac{1}{\sigma}}}{\sigma(1+r)}=t_{2}+\psi_{2}^{\prime}\left(e_{2}\right)-m_{2}^{*} .
$$

Consider now (53). Substituting $\lambda_{1}=-\lambda_{2}$ into (53) yields: 
$\frac{\alpha(1-\beta)}{\lambda_{1} e_{1}}=\psi_{1}^{\prime}\left(e_{1}\right)+t_{1}$

Plugging (60) into (63) amounts to:

$\frac{c_{0}}{\gamma} \frac{\alpha(1-\beta)}{e_{1}}=\psi_{1}^{\prime}\left(e_{1}\right)+t_{1}$.

Comparing (27) with (54) yields:

$\frac{\partial L^{W}}{\partial e_{2}}-\frac{\partial L^{R}}{\partial e_{2}}=0$

for

$m_{2}^{*}=\frac{e_{2}^{-\frac{1}{\sigma}} \theta^{\frac{\sigma-1}{\sigma}} E^{\frac{1}{\sigma}}}{\sigma(1+r)}$

Notice that $m_{2}^{*}$ equals the marginal benefit obtained by the externality. The foregoing discussion can be summarized in the following proposition.

Proposition 4. There exists $m_{2}^{*}$ such that the social optimum is reached in educational investment.

Proposition 4 shows that it is possible to replicate the social optimum in education decisions by manipulating tuition fees in such a way that tuition fees for education investment are subsidized.

\subsection{Regulated levels of education}

In this section we assume that the government imposes regulated levels of education, without altering tuition fees. First, we consider the case in which the government sets a minimum level of education investment that students need to acquire in order to obtain a college degree. We denote it as $e_{2} \geq e_{2}^{M}$, where the superscript $M$ stands for "minimum". In particular, the government sets as a minimum the socially optimal level. Since this is higher than the amount that the private level of education investment in the private equilibrium, none of the students will acquire more education investment than $e_{2}^{W}$, so that the constraint will be $e_{2}=e_{2}^{W}$. Therefore an individual's problem becomes:

$$
\begin{cases}\max _{c_{0}, e_{1}, e_{2}, s} & \alpha \ln \left(\theta^{\beta} e_{1}^{1-\beta}\right)+\gamma \ln \left(c_{0}\right)+k \ln (y) \\ \text { s.t. } & y=\left(\theta e_{2}\right)^{\frac{\sigma-1}{\sigma}} E^{\frac{1}{\sigma}}+s(1+r) \\ & E=\left(\iint\left(\theta e_{2}^{W}\right)^{\frac{\sigma-1}{\sigma}} f\left(\theta, Y_{0}\right) d \theta d Y_{0}\right)^{\frac{\sigma}{\sigma-1}} \\ & Y_{0}=c_{0}+t_{1} e_{1}+t_{2} e_{2}^{W}+\psi_{1}\left(e_{1}\right)+\psi_{2}\left(e_{2}^{W}\right)+s \\ & \frac{e_{2}^{-\frac{1}{\sigma}} \theta^{\frac{\sigma-1}{\sigma}} E^{\frac{1}{\sigma}}}{(1+r)}=\psi_{2}^{\prime}\left(e_{2}\right)-t_{2}\end{cases}
$$


The last constraint is the condition from Proposition 2 such that $e_{2}=e_{2}^{W}$. To solve the problem, write the Lagrangian function:

$$
\begin{aligned}
& L^{M}=\alpha \ln \left(\theta^{\beta} e_{1}^{1-\beta}\right)+\gamma \ln \left(c_{0}\right)+k \ln \left(\left(\theta e_{2}\right)^{\frac{\sigma-1}{\sigma}} E^{\frac{1}{\sigma}}+s(1+r)+T\left(\theta, Y_{0}\right)\right)+ \\
& \lambda_{1}\left[Y_{0}-\left(c_{0}+t_{1} e_{1}+t_{2} e_{2}^{W}+\psi_{1}\left(e_{1}\right)+\psi_{2}\left(e_{2}\right)+s+T_{0}\left(\theta, Y_{0}\right)\right)\right]+ \\
& \lambda_{2}\left[\frac{e_{2}^{-\frac{1}{\sigma}} \theta^{\frac{\sigma-1}{\sigma}} E^{\frac{1}{\sigma}}}{(1+r)}-\left(\psi_{2}^{\prime}\left(e_{2}\right)-t_{2}\right)\right]
\end{aligned}
$$

the first order conditions with respect to $c_{0}$ and $e_{1}$ are:

$$
\begin{aligned}
& \frac{\partial L^{M}}{\partial c_{0}}=\frac{\gamma}{c_{0}}-\lambda_{1}=0 \\
& \frac{\partial L^{M}}{\partial e_{1}}=\frac{\alpha(1-\beta)}{e_{1}}-\lambda_{1}\left(t_{1}+\psi_{1}^{\prime}\left(e_{1}\right)\right)=0
\end{aligned}
$$

Notice that (68) amounts to $\lambda_{1}=\frac{\gamma}{c_{0}}$. By substituting into (69) yields

$\frac{c_{0}}{\gamma} \frac{\alpha(1-\beta)}{e_{1}}=t_{1}+\psi_{1}^{\prime}\left(e_{1}\right)$,

That is the social optimum level. The ongoing discussion can be summarized as follows.

Proposition 5. Suppose the government introduce a minimum level of education investment $e_{2}^{M}=e_{2}^{W}$ as a requirement in order to obtain a college degree. Then the minimum level on $e_{2}$ would induce efficiency.

\section{Concluding remarks}

In this paper we have analyzed a model in which students choose their university courses according to both investment and consumption intentions. We have shown the presence of an inefficiency in the education decisions, and the way to solve the inefficiency through the design of optimal tuition fees being differentiated according to the intrinsic characteristics of a university course. Although the paper's aim was limited to show this specific inefficiency, the approach considered may suggest a new perspective on the design of education policies. 


\section{REFERENCES}

Acemoglu, D. and Pischke, S. 2001. Changes in the wage structure, family income, and children's education. European Economic Review 45: 890-904.

Antonji, J. G., Blom, E. and Meghir, C. 2012. Heterogeneity in Human Capital Investment: High School Curriculum, College Major, and Careers. Annual Review of Economics 4: 185-223.

Baird, L. 1967. Family Income and the Characteristics of College Bound Students. American College Testing Program. ERIC Document Reproduction Service ED012969. Iowa City, Iowa.

Becker, G. A. 1967. Human Capital and the Personal Distribution of Income. Ann Arbor, MI: University of Michingan Press.

Becker, G. A. 1993. Human Capital: A Theoretical and Empirical Analysis, with Special Reference to Education. $3^{\wedge}\{\mathrm{rd}\}$ edition. Columbia University Press for the National Bureau of Economic Research. New York.

Benabou, R. 1996. Heterogeneity, Stratification, and Growth: Macroeconomic Implications of Community Structure and School Finance. American Economic Review 86: 584-609.

Blanden, J. and Machin, S. 2004. Educational inequality and the expansion of UK higher education. Scottish Journal of Political Economy 51: 230-249.

Cameron, S. and Heckman, J. 2001. The Dynamics of Educational Attainment for Black, Hispanic and White Males. Journal of Political Economy 109: 455-99.

Carneiro, P. and Heckman, J. 2003. Human Capital Policy. in Heckman J., Krueger A. (eds.), Inequality in America: what role for human capital policies? MIT Press.

Catsambis S. 1994. The path to math: gender and racial-ethnic differences in mathematics participation from middle school to high school. Sociology of Education 67:199-215.

Delaney, A. M. 1998. Parental Income and Students' College Choice Process: Research Findings To Guide Recruitment Strategies. AIR Annual Forum Paper.

Ellwood, D. and Kane, T. 2000. Who Is Getting a College Education? Family Background and the Growing Gaps in Enrollment. In Danziger, S. and J. Waldfogel (eds.), Securing the Future. New York: Russell Sage Foundation.

Hearn, J. C. 1984. The Relative Roles of Academic, Ascribed and Socio-Economic Characteristics in College Destination. Sociology of Education 57: 22-30.

Hearn, J. C. 1988. Attendance at Higher Cost Colleges: Ascribed, Socio-Economic and Academic Influences on Student Enrollment Patterns. Economics of Education Review 7: 65-76.

Leppel, K., Williams, Mary L. and Waldauer, C. 2001. Journal of Family and Economic Issues 22 : 373-394. 
Leppel, K., Williams, Mary L. and Waldauer, C. 2005. Socioeconomic Status and College Major: A Reexamination of the Empirical Evidence. Journal of The First-Year Experience and Students in Transition 17: 49-72.

McMahon, W.W. 1976. Influences on investment by blacks in higher education. American Economic Review 66: 320-324.

McMahon, W.W. 1984. Why families invest in education. In S. Sudman and M. A. Spaeth (eds.), The collection and analysis of economic and consumer behavior data: In memory of Robert Ferber. Urbana, IL: Bureau of Economic and Business Research, University of Illinois.

McMahon, W.W. 1991. Improving higher education through increased efficiency. In D.H. Finifter, R.G. Baldwin, and J.R. Thelin (eds.), The uneasy public policy triangle in higher education: Quality, diversity, and budgetary efficiency. New York: ACE/Macmillan.

Panzar, J. C. and Willig, R. D. 1976. Vindication of a "Common Mistake" in Welfare Economics. Journal of Political Economy 84: 1361-1363.

Sanders, C. and Taber, C. 2012. Life-Cycle Wage Growth and Heterogeneous Human Capital. Annual Review of Economics 4: 399-425.

Trusty, J, Robinson, Chester, R, Plata Maximo and Kon-Mun Ng. 2000. Effects of Gender, Socioeconomic Status, and Early Academic Performance on Postsecondary Educational Choice. Journal of Counseling and Development 78: 463-472.

Vona, F. 2011. Does the Expansion of Higher Education Reduce Educational Inequality? Evidence from 12 European Countries. Working Paper OFCE - Centre de recherche en économie de Sciences Po 12.

Yamaguchi, S. 2012. Tasks and Heterogeneous Human Capital. Journal of Labor Economics 30: 153. 


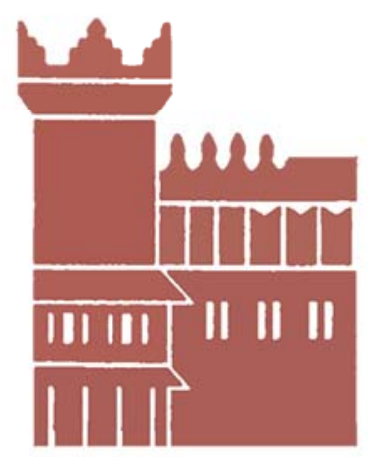

Alma Mater Studiorum - Università di Bologna DEPARTMENT OF ECONOMICS

Strada Maggiore 45

40125 Bologna - Italy

Tel. +39051 2092604

Fax +390512092664

http://www.dse.unibo.it 